\title{
Production of hydrogen in a granular sludge-based anaerobic continuous stirred tank reactor
}

\author{
Kuan-Yeow Show $^{\mathrm{a}, *}$, Zhen-Peng Zhang ${ }^{\mathrm{b}, \mathrm{c}}$, Joo-Hwa Tay ${ }^{\mathrm{b}, \mathrm{c}}$, David Tee Liang ${ }^{\mathrm{c}}$, \\ Duu-Jong Lee ${ }^{\mathrm{d}}$, Wen-Ju Jiang ${ }^{\mathrm{e}}$ \\ ${ }^{a}$ Faculty of Engineering and Science, University of Tunku Abdul Rahman, 53300 Setapak, Kuala Lumpur, Malaysia \\ ${ }^{\mathrm{b}}$ School of Civil and Environmental Engineering, Nanyang Technological University, 639798, Singapore \\ ${ }^{\mathrm{c}}$ Institute of Environmental Science and Engineering, Nanyang Technological University, 637723, Singapore \\ ${ }^{\mathrm{d}}$ Department of Chemical Engineering, National Taiwan University, Taipei 10617, Taiwan, RO China \\ ${ }^{\mathrm{e}}$ Department of Environmental Science and Engineering, Sichuan University, Chengdu 610065, PR China
}

Received 2 November 2006; received in revised form 24 May 2007; accepted 2 July 2007

Available online 27 August 2007

\begin{abstract}
An investigation on biohydrogen production was conducted in a granular sludge-based continuous stirred tank reactor (CSTR). The reactor performance was assessed at five different glucose concentrations of $2.5,5,10,20$ and $40 \mathrm{~g} / \mathrm{L}$ and four hydraulic retention times (HRTs) of 0.25 , $0.5,1$ and $2 \mathrm{~h}$, resulting in the organic loading rates (OLRs) ranged between 2.5 and $20 \mathrm{~g}$-glucose/L h. Carbon flow was traced by analyzing the composition of gaseous and soluble metabolites as well as the cell yield. Butyrate, acetate and ethanol were found to be the major soluble metabolite products in the biochemical synthesis of hydrogen. Carbon balance analysis showed that more than half of the glucose carbon was converted into unidentified soluble products at an OLR of $2.5 \mathrm{~g}$-glucose/L h. It was found that high hydrogen yields corresponded to a sludge loading rate in between 0.6 and $0.8 \mathrm{~g}$-glucose/g-VSSh. Substantial suppression in hydrogen yield was noted as the sludge loading rate fell beyond the optimum range. It is deduced that decreasing the sludge loading rate induced the metabolic shift of biochemical reactions at an OLR of $2.5 \mathrm{~g}$-glucose $/ \mathrm{Lh}$, which resulted in a substantial reduction in hydrogen yield to $0.36-0.41 \mathrm{~mol}-\mathrm{H}_{2} / \mathrm{mol}$-glucose. Optimal operation conditions for peak hydrogen yield $\left(1.84 \mathrm{~mol}-\mathrm{H}_{2} / \mathrm{mol}\right.$-glucose $)$ and hydrogen production rate $(3.26 \mathrm{~L} / \mathrm{Lh})$ were achieved at an OLR of $20 \mathrm{~g}$-glucose/L h, which corresponded to an HRT of $0.5 \mathrm{~h}$ and an influent glucose concentration of $10 \mathrm{~g} / \mathrm{L}$. Influence of HRT and substrate concentration on the reactor performance was interrelated and the adverse impact on hydrogen production was noted as substrate concentration was higher than $20 \mathrm{~g} / \mathrm{L}$ or HRT was shorter than $0.5 \mathrm{~h}$. The experimental study indicated that a higher OLR derived from appropriate HRTs and substrate concentrations was desirable for hydrogen production in such a granule-based CSTR.
\end{abstract}

(C) 2007 International Association for Hydrogen Energy. Published by Elsevier Ltd. All rights reserved.

Keywords: Biohydrogen; Granular sludge; Organic loading rate; Hydraulic retention time; Substrate concentration; Sludge loading rate

\section{Introduction}

Currently, fossil fuel-dependent economy attracts worldwide concerns ranging from its sustainability to global warming. Hydrogen is a promising alternative to conventional fossil fuels because it has the potential to eliminate all of the problems that the fossil fuels create. However, a major doubt on hydrogen as a clean energy alternative is how it is produced. This is largely owing to the fact that most of the hydrogen gas at present is

\footnotetext{
* Corresponding author.

E-mail address: ckyshow@ntu.edu.sg (K.-Y. Show).
}

currently generated from fossil fuels by thermochemical processes. Because of their sustainable and pollution-free properties, biological processes, such as biophotosynthesis, photodecomposition and anaerobic fermentation routes to harness hydrogen from renewable sources, i.e. water or organic compounds have lately received considerable attention [1]. Among these processes, anaerobic hydrogen fermentation seems to be more favorable, since hydrogen is yielded at a high rate with a concomitant reduction in environmental organic pollutants.

Most recent studies on anaerobic hydrogen fermentation focused on the improvement in systematic hydrogen yield and volumetric production rate. Studies on continuous hydrogen 
fermentation indicated that anaerobic hydrogen-producing cultures are greatly influenced by several operational parameters, such as temperature [2], $\mathrm{pH}[3]$, hydraulic retention time (HRT) [4], type of substrate [5] and substrate concentration [6] and organic loading rate (OLR) [7].

OLR is an important parameter dictating the system performance and operational cost of fermentative hydrogen production. As OLR is a function of HRT and influent substrate concentration (ISC), OLR, HRT and ISC are interrelated. However, previous studies on OLR evaluation were mostly carried out by changing one variable while keeping another consistent. The evaluation on HRT-OLR or ISC-OLR is hence incomprehensive, as contribution derived from other variables has been neglected. In fact, it had been reported that hydrogen yield increased consistently with the reduction in OLR, as HRT increased from 2 to $24 \mathrm{~h}$ at an ISC of $34 \mathrm{~g}-\mathrm{COD} / \mathrm{L}$ [8], while at a higher ISC of $50 \mathrm{~g}-\mathrm{COD} / \mathrm{L}$, it increased initially with the HRT increasing from 8 to $18 \mathrm{~h}$, but fell significantly beyond $18 \mathrm{~h}$ HRT [9]. It is likely that these contradictory conclusions resulted from the effect of other operational parameters rather than HRT alone, such as substrate concentration and the resulting OLR. Likewise, inconsistent results had been noticed on the effect of ISC on hydrogen production at a different HRT $[6,10]$.

On the other hand, a variety of high-rate bioreactor systems, with a common property of enhanced biomass retention were developed in recent years. These included anaerobic fixed-bed reactor [11], anaerobic fluidized bed reactor [12], and upflow anaerobic sludge blanket (UASB) reactor [13]. Fang and his team $[14,15]$ had successfully cultivated hydrogen-producing granular sludge in a continuous stirred tank reactor (CSTR). The granule-based CSTR exhibited higher hydrogen production rate $(0.54 \mathrm{~L} / \mathrm{L} \mathrm{h})$ than that of conventional CSTR $(0.15 \mathrm{~L} / \mathrm{L} \mathrm{h})$ [16], but the rate was much lower as compared to other immobilizedcell systems $(0.93-7.33 \mathrm{~L} / \mathrm{Lh})[11,12,17,18]$. While Liu and Fang [15] had studied the effect of HRT and ISC on biohydrogen production of granular sludge at a consistent OLR level, the effect of OLR remained unclear. Furthermore, Van Ginkel and Logan [7] found that hydrogen yield increased with the reduction in OLR from 9.5 to $0.25 \mathrm{~g}$-glucose/ $\mathrm{Lh}$ for suspended cells in chemostat reactors. Whether such an enhanced hydrogen yield could be achieved for immobilized cultures remains uncertain. It follows that a comprehensive evaluation of organic loading through systematically changing the HRT and ISC on the performance of granule-based CSTR is worth pursuing.

The aim of the present study is to investigate the influence of HRT, ISC and hence OLR on hydrogen production performance of granular sludge in a CSTR, which was conducted by examining different HRTs and substrate concentrations and associated OLRs.

\section{Materials and methods}

\subsection{Inoculum and substrate}

The seed sludge was originally obtained from a local wastewater treatment plant, which was acclimated with glucose

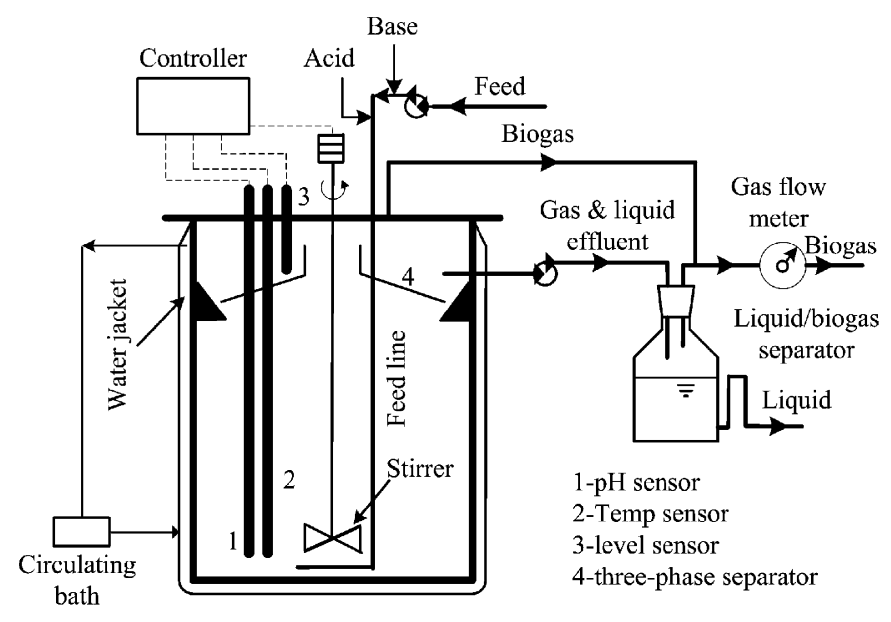

Fig. 1. Schematics of anaerobic continuous stirred tank reactor system.

(10 g-glucose/L) in an anaerobic CSTR at $\mathrm{pH} 5.5$ for more than 2 months as reported in a previous study [4]. The granular sludge used in the current study was derived by a procedure of acid incubation on the acclimated seed sludge, which had been described in a separate study [19]. The substrate used for hydrogen fermentation consisted of glucose ranging from 2.5 to $40 \mathrm{~g} / \mathrm{L}$ and nutrients at a constant carbon : nutrient ratio as described in previous studies $[4,18]$.

\subsection{Experimental setup and operation}

A culture vessel (Biostat B, B. Braun Biotech, Germany) equipped with temperature and $\mathrm{pH}$ controllers was used as shown in Fig. 1. It had a working volume of $6 \mathrm{~L}$ with an internal diameter of $160 \mathrm{~mm}$ and a height of $345 \mathrm{~mm}$. A level sensor and effluent peristaltic pump were used to control the culture volume at a constant level. The reactor was operated at a constant temperature of $37^{\circ} \mathrm{C}$ and $\mathrm{pH}$ of $5.5 \pm 0.05$. The reactor culture was mixed continuously at $160 \mathrm{rpm}$ using two disc impellers, each having 6 flat blades $(\Phi=64 \mathrm{~mm})$, which were located at a height of $20 \mathrm{~mm}$ above the reactor bottom. A three-phase separator was installed inside the CSTR to promote retention of granular sludge.

After starting up granule-based CSTR, 13 test runs were conducted in series to assess the influence of HRT, ISC and OLR on hydrogen production. The CSTR was operated at five different influent glucose concentrations $(2.5,5,10,20,40 \mathrm{~g} / \mathrm{L})$ and four different HRTs $(0.25,0.5,1,2 \mathrm{~h})$, resulting in OLRs ranging from 2.5 to $20 \mathrm{~g}$-glucose/L h. The OLRs were computed from the concentration of glucose loaded into the reactor per unit HRT. Starting from an OLR of $20 \mathrm{~g}$-glucose/L h which corresponded to an HRT of $0.25 \mathrm{~h}$ and an influent glucose concentration of $5 \mathrm{~g} / \mathrm{L}$, the reactor was operated by stepwise OLR reduction. The loading and operating conditions are shown in Table 1. Steady-state conditions were considered attained when the biogas production and glucose conversion rate were consistent within $5 \%$ for three consecutive days. Data were collected for a week after the steady-state conditions were reached for each test run. 
Table 1

Loading and operating conditions

\begin{tabular}{lll}
\hline OLR (g-glucose/L h) & HRT (h) & ISC (g-glucose/L) \\
\hline 20 & 0.25 & 5 \\
& 0.5 & 10 \\
& 1 & 20 \\
& 2 & 40 \\
10 & 2 & 20 \\
& 1 & 10 \\
& 0.5 & 5 \\
& 0.25 & 2.5 \\
5 & 0.5 & 2.5 \\
& 1 & 5 \\
& 2 & 10 \\
2.5 & 2 & 5 \\
& 1 & 2.5 \\
\hline
\end{tabular}

\subsection{Analytical methods}

Biogas flow was measured by a wet gas meter (Ritter TG 05 , Germany). The biogas composition was analyzed by a gas chromatography (Varian 4900, USA) equipped with a thermal conductivity detector. Hydrogen was analyzed using a Molsieve 5A Plot column with argon as carrier gas set at $60^{\circ} \mathrm{C}$; methane and carbon dioxide were analyzed using a Propac Q column with helium as carrier gas also set at $60^{\circ} \mathrm{C}$. Soluble metabolic products, viz. ethanol and volatile fatty acids (VFAs), including acetate, propionate, butyrate, valerate and hexanoate were determined by a gas chromatograph (Agilent 6890 , USA) equipped with a mass selective detector $\left(220^{\circ} \mathrm{C}\right)$, an injector $\left(200^{\circ} \mathrm{C}\right)$ and a $30 \mathrm{~m} \times 0.25 \mu \mathrm{m}$ HP-FFAP fusedsilica capillary column. The temperature of the oven was initially maintained at $60^{\circ} \mathrm{C}$ for $4 \mathrm{~min}$ and then increased to $168^{\circ} \mathrm{C}$ at a ramp of $6^{\circ} \mathrm{C} / \mathrm{min}$ and lastly heated to $200^{\circ} \mathrm{C}$ at $10^{\circ} \mathrm{C} / \mathrm{min}$ and maintained for $2 \mathrm{~min}$. Helium was used as the carrier gas. Glucose concentration was determined following the phenol-sulfuric acid method reported by Dubois et al. [20]. Total organic carbon (TOC) was measured by a TOC analyzer (Shimadzu VCSH, Japan). Measurements of volatile suspended solids (VSS) were performed in accordance with the Standard Methods [21].

\section{Results and discussion}

To examine the influence of HRT, ISC and OLR on hydrogen production of granular sludge, a series of experiments comprising 13 runs were conducted in the CSTR. Influence of the above variables on biogas composition, hydrogen yield, hydrogen production rate, reactor biomass retention and distribution of carbon flow was assessed. The HRT and the influent glucose concentration ranged from 0.25 to $2 \mathrm{~h}$ and 2.5 to $40 \mathrm{~g} / \mathrm{L}$, respectively, resulting in four different OLR levels from 2.5 to 20 g-glucose/L h.
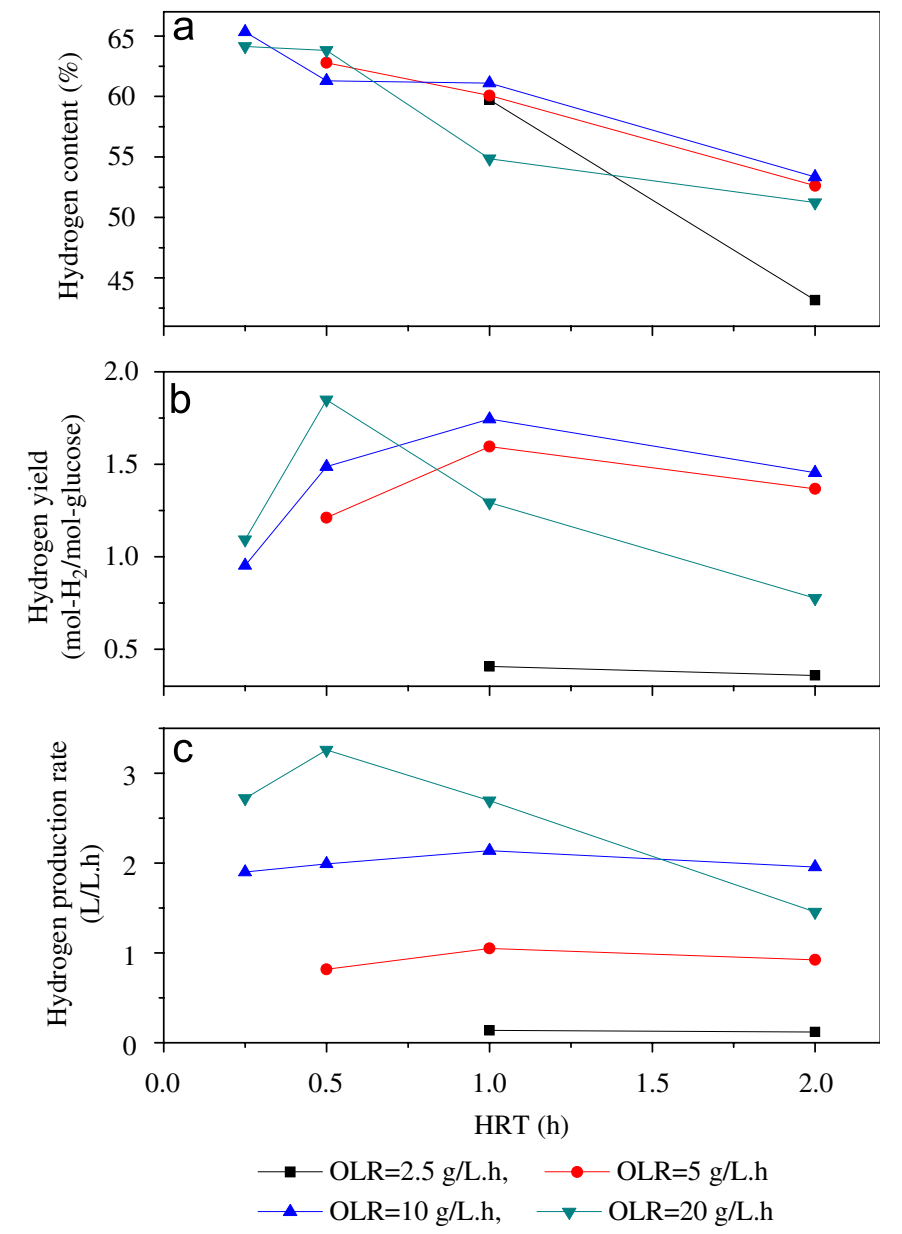

Fig. 2. Influence of HRT, influent glucose concentration and resulting OLR on (a) hydrogen content, (b) hydrogen yield, and (c) hydrogen production rate.

\subsection{Production of hydrogen}

Fig. 2 depicts the variation of hydrogen content, hydrogen yield and hydrogen production rate with HRT, and indirectly with ISC under four OLR levels. The biogas produced consisted of hydrogen and carbon dioxide, whereas methane was undetectable throughout the study. As shown in Fig. 2a, hydrogen content was insensitive to the OLR. A general tendency, at a given OLR level, was observed such that hydrogen content decreased with increasing HRT and glucose concentration. For instance, the hydrogen content decreased from $64.1 \%$ to $51.2 \%$ at an OLR of $20 \mathrm{~g}$-glucose/Lh when the HRT was extended from 0.25 to $2 \mathrm{~h}$, corresponding to an increase of glucose concentration from 5 to $40 \mathrm{~g} / \mathrm{L}$. The influence of ISC, at a given HRT, on biogas composition can be indirectly evaluated from Fig. 2a, showing that relatively consistent hydrogen content was achieved at each HRT. The hydrogen content varied slightly, generally less than 5\% at each HRT as the influent glucose concentration changed. These results suggest that the effect of HRT on biogas composition was much more pronounced than that of the influent glucose concentration and OLR.

As depicted in Figs. $2 b$ and c, a general trend was found such that hydrogen yield and hydrogen production rate decreased 


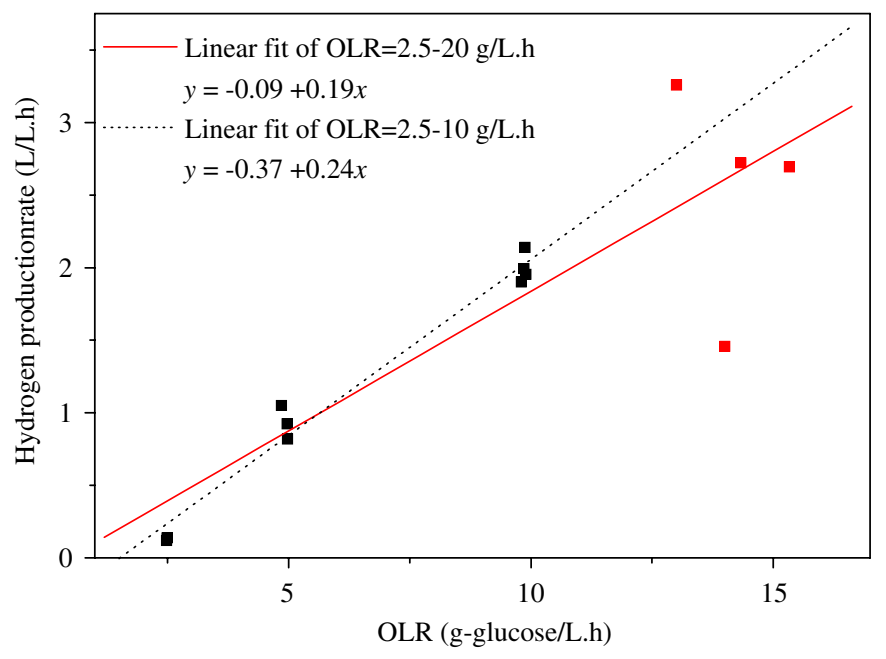

Fig. 3. Hydrogen production rate as a function of OLR (solid line, $R=0.89$ and $p<0.0001$; dot line, $R=0.99$ and $p<0.0001)$.

with the reduction in OLR from 20 to $2.5 \mathrm{~g}$-glucose/L h. Hydrogen yield and hydrogen production rate reached the maximum values of $1.84 \mathrm{~mol}-\mathrm{H}_{2} / \mathrm{mol}$-glucose and $3.26 \mathrm{~L} / \mathrm{L} \mathrm{h}$, respectively, at the highest OLR level, but they both decreased drastically to $0.36-1.41 \mathrm{~mol}-\mathrm{H}_{2} / \mathrm{mol}$-glucose and $0.12-0.14 \mathrm{~L} / \mathrm{L} \mathrm{h}$, respectively, as the OLR was reduced to $2.5 \mathrm{~g}$-glucose/L h. Hydrogen yield was sensitive to HRT, and hence to influent glucose concentration, while hydrogen production rate was less influenced by the HRT and glucose concentration at lower OLRs between 2.5 and $10 \mathrm{~g}$-glucose/L h. At a higher OLR of $20 \mathrm{~g}$-glucose/ $\mathrm{L} \mathrm{h}$, a substantial reduction in hydrogen production was noted at an HRT of $2 \mathrm{~h}$ and a corresponding ISC of $40 \mathrm{~g} / \mathrm{L}$. This resulted in a lowered linear response of hydrogen production rate to the overall OLR $(R=0.89$, possibility $(p)<0.0001)$ (Fig. 3). In contrast, a very high correlation coefficient $(R=0.99)$ was found existing between hydrogen production rate and OLR, ranging from 2.5 to $10 \mathrm{~g}$-glucose $/ \mathrm{L} \mathrm{h}$. These findings imply that hydrogen production rate might not essentially increase linearly with the OLR once the impact derived from OLR itself and its variables, i.e. HRT or substrate concentration has not been established.

The respective influence of HRT and ISC on hydrogen yield was assessed and plotted in Fig. 4. For a given HRT between 0.25 and $2 \mathrm{~h}$, hydrogen yield increased with the glucose concentration from 2.5 to $10 \mathrm{~g} / \mathrm{L}$, whereas hydrogen yield was found to decrease substantially when influent glucose concentration increased to $20 \mathrm{~g} / \mathrm{L}$ at $1 \mathrm{~h} H R T$, and to $40 \mathrm{~g} / \mathrm{L}$ at $2 \mathrm{~h}$ HRT. The adverse influence of higher ISC is thus indicated. As hydrogen yield reached the peak at $2 \mathrm{~h}$ HRT, the influent glucose concentration corresponded to $20 \mathrm{~g} / \mathrm{L}$; such a concentration had resulted in a significant decrease in hydrogen yield at $1 \mathrm{~h}$ HRT. These findings thus imply that the magnitude of substrate concentration to suppress hydrogen production was related to the HRT employed. The values obtained are generally in agreement with the reported inhibitory concentrations of $20 \mathrm{~g}$-glucose/L [22] and $35 \mathrm{~g}$-COD/L [6] which were noted at $1.1 \mathrm{~h} \mathrm{HRT}$ and $12 \mathrm{~h}$ HRT conditions, respectively. The shocked

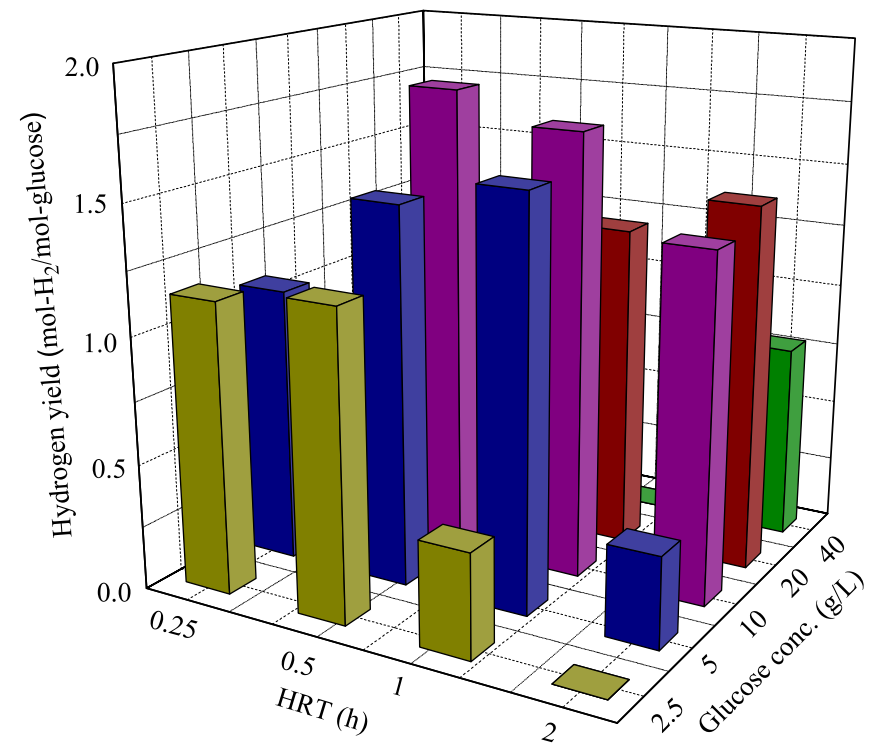

Fig. 4. Hydrogen yield with a matrix of HRT and ISC.

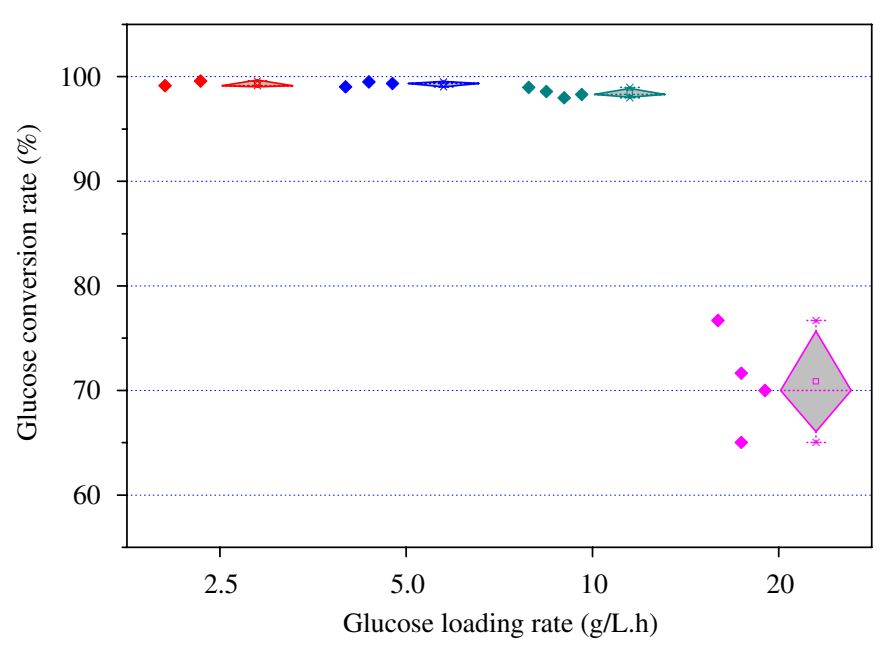

Fig. 5. Glucose conversion rate as a function of organic loading rate.

impact of higher substrate concentration on hydrogen production was probably relieved through extending the HRT. Likewise, the impact of substrate concentration has to be taken into consideration with respect to the influence of HRT on hydrogen yield. At low influent glucose concentrations between 2.5 and $5 \mathrm{~g} / \mathrm{L}$, hydrogen yield increased initially as the HRT was shortened from 2 to $0.5 \mathrm{~h}$, and then substantially decreased at an HRT of $0.25 \mathrm{~h}$. As with a glucose concentration of $10 \mathrm{~g} / \mathrm{L}$, hydrogen yield increased with the reduction in HRT, while the opposite result was obtained, if the glucose concentration was larger than $20 \mathrm{~g} / \mathrm{L}$.

From these experimental results, it is deduced that HRT and influent glucose concentration are interrelated and have an integrated impact on hydrogen yield. These findings could provide a new perspective to some current debatable claims. As indicated by previous studies on the HRT effect, with a relatively low substrate concentration of $20 \mathrm{~g}$-glucose/L, hydrogen yield 


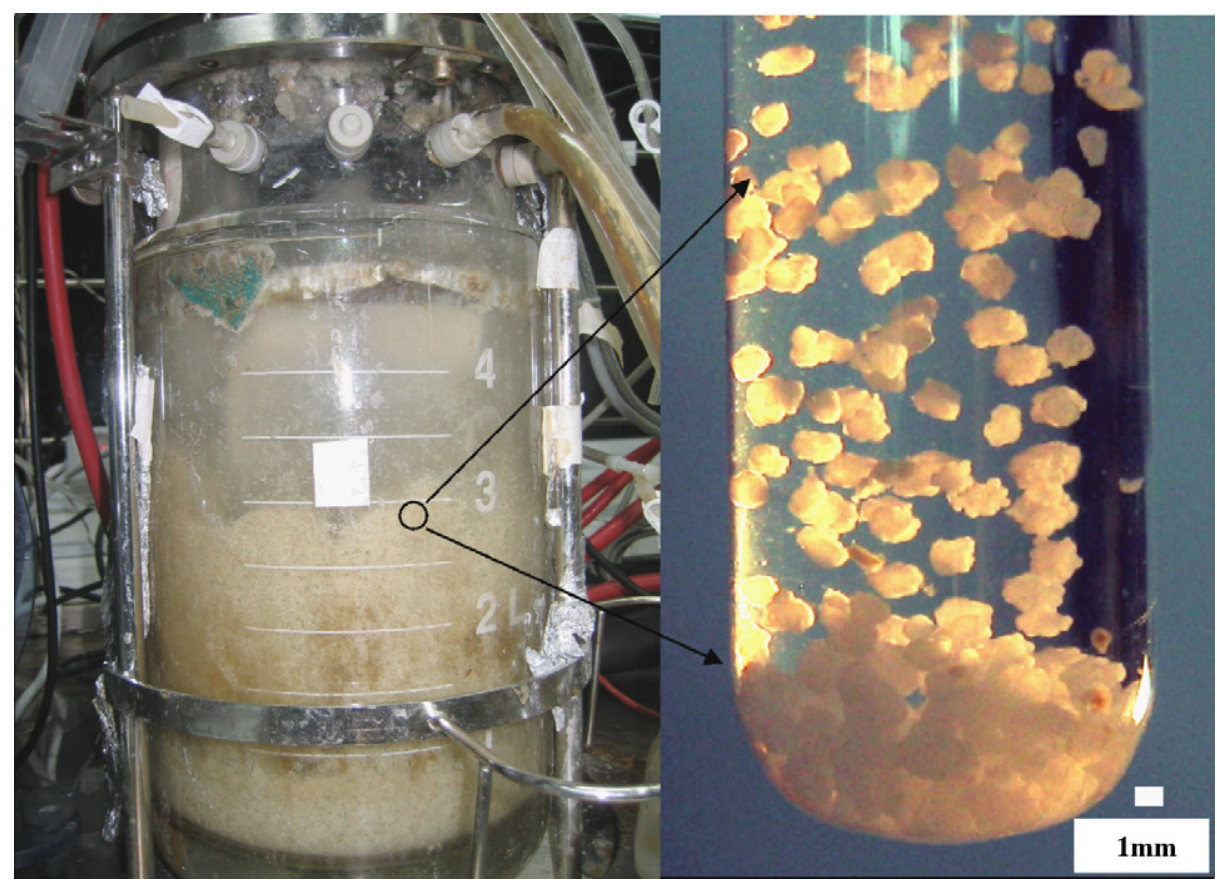

Fig. 6. Photograph of granule-based CSTR and granules inside (scale bar $=1 \mathrm{~mm}$ ).

decreased consistently in an HRT range of 12-48 h [23], while at a substrate concentration of $37 \mathrm{~g}-\mathrm{COD} / \mathrm{L}$, hydrogen yield increased with HRT, from 2 to $24 \mathrm{~h}$ HRT [8]. Likewise, with a more concentrated substrate $(50 \mathrm{~g}-\mathrm{COD} / \mathrm{L})$ hydrogen yield increased initially between 8 and $18 \mathrm{~h}$ HRT and then fell significantly beyond $18 \mathrm{~h}$ HRT [10]. In other studies concerning the effect of substrate concentration, Kim and his coworkers [6] found hydrogen yield to increase with increasing glucose concentration from 10 to $35 \mathrm{~g} / \mathrm{L}$ at an HRT of $12 \mathrm{~h}$, whereas at shorter HRTs of $2 \mathrm{~h} \mathrm{[10]} \mathrm{and} 4 \mathrm{~h}$ [8], hydrogen yield decreased consistently as the ISC increased from 6.9 to 27.4 g-glucose/L and 14 to $36 \mathrm{~g}-\mathrm{COD} / \mathrm{L}$, respectively.

A substantial decrease in hydrogen production might be caused by a shorter HRT or a higher ISC. This could be attributed to deficient fermentation or occurrence of substrate/product inhibition during the hydrogen production [12,24]. Hence, appropriate control of HRT, substrate concentration and the associated OLR is crucial for hydrogen production in the granule-based CSTR system. Ignoring any of these parameters might result in an inferior performance of the biosystems. For example, an OLR of $20 \mathrm{~g}$-glucose/ $\mathrm{Lh}$ was found most favorable for hydrogen fermentation in the present study, but such an optimum OLR condition might have been missed if only influent concentration were examined at a fixed HRT of $2 \mathrm{~h}$.

The optimal operating conditions were found at the OLR of $20 \mathrm{~g}$-glucose $/ \mathrm{L} \mathrm{h}$, corresponding to $0.5 \mathrm{~h}$ HRT and $10 \mathrm{~g} / \mathrm{L}$ influent glucose concentration where both hydrogen yield and hydrogen production rate reached the maximum values. Glucose conversion rate, however, was found to be $70.9 \pm 4.8 \%$ at the highest OLR. In contrast, more than $98 \%$ glucose was utilized for OLR in a range of 2.5-10 g-glucose/L h (Fig. 5).

\subsection{Biomass concentration}

As shown in Fig. 6, a relatively consistent and compact granular sludge layer was formed, which occupied a space of 2.4-3 L under the OLR levels tested (Fig. 7a). The biomass concentrations were found between 19 and $34 \mathrm{~g} / \mathrm{L}-\mathrm{VSS}$ in the granular sludge layer, which was called as granular sludge layer concentration in the context. Extending the HRT resulted in a slight increase in the granular sludge layer concentration, so did glucose concentration. Much more granular sludge was accumulated with the increase in OLR (Fig. 7a). Over the granular sludge layer, fewer granules were suspended in the bulk liquid, with a concentration of $0.9-1.5 \mathrm{~g}-\mathrm{VSS} / \mathrm{L}$. Therefore, the amount of biomass was mainly regulated by the granular sludge accumulated in the granular sludge layer.

Overall biomass retention in the reactor ranged from 46 to $96 \mathrm{~g}$-VSS, and it was substantially correlated to the OLRs as shown in Fig. 7b, and the corresponding reactor biomass concentrations were in a range of 7.7-16.0 g-VSS/L. Compared to other granular sludge systems, such concentrations of granular sludge were comparable to the values (5.1 and $17.0 \mathrm{~g}-\mathrm{VSS} / \mathrm{L})$ reported in column-type reactors $[25,26]$, but lower than $20 \mathrm{~g}$ VSS/L [14] and 35.8 g-VSS/L [27] obtained in CSTRs. The retention of biomass might be influenced by the reactor configuration and operational parameters, such as reactor mixing, impeller location, three-phase separator, HRT, OLR, etc. Reducing the stirring rate might increase the level and corresponding concentration of granular sludge layer to a certain extent, but it was not always feasible because the maintenance of culture mixing for those sensors had to be taken care of in such a CSTR equipped with $\mathrm{pH}$ and temperature sensors within the reactor. Improvement on reactor control modes may increase 

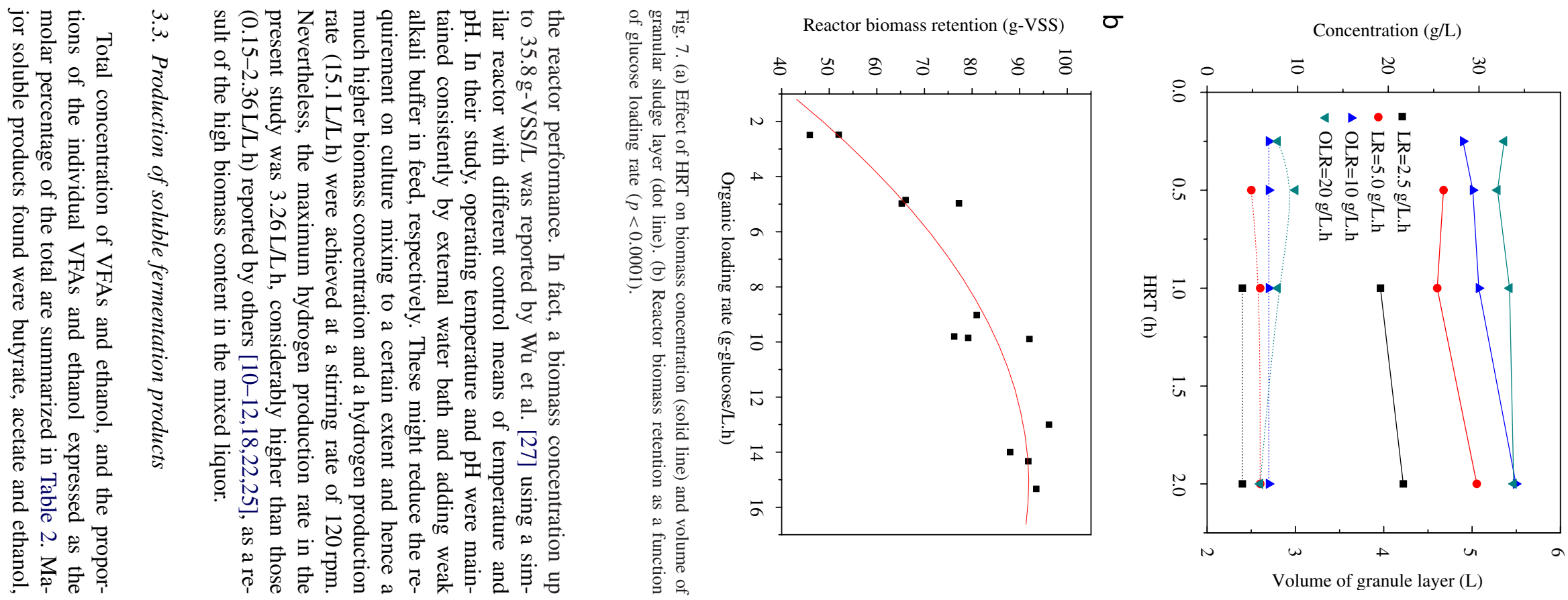

Table 2

Soluble product distribution in effluent

\begin{tabular}{|c|c|c|c|c|c|c|c|c|c|c|c|}
\hline HRT (h) & $\begin{array}{l}\text { Glucose } \\
\text { conc. } \\
\text { (g/L) }\end{array}$ & $\begin{array}{l}\text { OLR } \\
(\mathrm{g} / \mathrm{L} / \mathrm{h})\end{array}$ & Total $(\mathrm{mM})$ & Ethanol $(\%)^{\mathrm{a}}$ & Acetate $(\%)$ & Propionate $(\%)$ & Butyrate $(\%)$ & Valerate $(\%)$ & Hexanoate (\%) & $(\mathrm{Eth} \pm \mathrm{AA})(\%)^{\mathrm{b}}$ & $\mathrm{BA} / \mathrm{AA}^{\mathrm{c}}$ \\
\hline 1 & 2.5 & 2.5 & $8.27 \pm 0.64^{\mathrm{d}}$ & $18.67 \pm 2.59$ & $50.33 \pm 1.75$ & $-^{\mathrm{e}}$ & $31.00 \pm 4.33$ & - & - & $69.00 \pm 4.33$ & $0.62 \pm 0.11$ \\
\hline 2 & 5 & 2.5 & $16.54 \pm 1.99$ & $11.52 \pm 1.70$ & $38.54 \pm 1.97$ & $8.10 \pm 0.41$ & $37.68 \pm 4.52$ & $2.93 \pm 0.38$ & $1.26 \pm 0.12$ & $50.06 \pm 3.65$ & $0.98 \pm 0.16$ \\
\hline 0.5 & 2.5 & 5 & $17.94 \pm 0.39$ & $12.72 \pm 1.34$ & $22.70 \pm 0.72$ & $1.94 \pm 3.36$ & $52.35 \pm 1.63$ & $7.81 \pm 0.46$ & $2.48 \pm 0.55$ & $35.42 \pm 1.86$ & $2.31 \pm 0.06$ \\
\hline 1 & 5 & 5 & $30.56 \pm 0.29$ & $12.15 \pm 0.21$ & $22.99 \pm 0.47$ & - & $50.00 \pm 0.62$ & $6.18 \pm 0.26$ & $8.67 \pm 0.27$ & $35.14 \pm 0.66$ & $2.18 \pm 0.07$ \\
\hline 2 & 10 & 5 & $72.96 \pm 1.86$ & $15.59 \pm 0.84$ & $22.23 \pm 1.16$ & - & $54.95 \pm 0.94$ & $2.94 \pm 0.19$ & $4.29 \pm 0.27$ & $37.82 \pm 1.02$ & $2.48 \pm 0.16$ \\
\hline 0.25 & 2.5 & 10 & $18.38 \pm 0.61$ & $11.61 \pm 0.76$ & $19.59 \pm 1.35$ & - & $58.76 \pm 1.51$ & $7.62 \pm 0.48$ & $2.42 \pm 0.56$ & $31.20 \pm 2.07$ & $3.01 \pm 0.29$ \\
\hline 0.5 & 5 & 10 & $31.99 \pm 0.16$ & $12.20 \pm 0.1$ & $22.91 \pm 0.28$ & - & $49.70 \pm 0.21$ & $6.12 \pm 0.12$ & $9.08 \pm 0.19$ & $35.11 \pm 0.30$ & $2.17 \pm 0.03$ \\
\hline 1 & 10 & 10 & $68.49 \pm 1.32$ & $12.81 \pm 0.19$ & $25.87 \pm 1.69$ & - & $53.68 \pm 1.61$ & $3.07 \pm 0.19$ & $4.57 \pm 0.11$ & $38.68 \pm 1.82$ & $2.08 \pm 0.20$ \\
\hline 2 & 20 & 10 & $159.57 \pm 7.27$ & $23.54 \pm 0.26$ & $16.80 \pm 0.95$ & $0.46 \pm 0.40$ & $52.63 \pm 1.00$ & $2.71 \pm 0.24$ & $3.84 \pm 0.12$ & $40.35 \pm 0.70$ & $3.14 \pm 0.24$ \\
\hline 0.25 & 5 & 20 & $22.38 \pm 0.22$ & $22.77 \pm 0.31$ & $17.59 \pm 0.07$ & - & $36.98 \pm 0.17$ & $9.63 \pm 0.48$ & $13.03 \pm 0.34$ & $40.36 \pm 0.25$ & $2.10 \pm 0.01$ \\
\hline 0.5 & 10 & 20 & $51.14 \pm 2.31$ & $12.94 \pm 0.44$ & $25.67 \pm 0.71$ & - & $51.00 \pm 0.22$ & $3.79 \pm 0.16$ & $6.60 \pm 0.57$ & $38.61 \pm 0.58$ & $1.99 \pm 0.06$ \\
\hline 1 & 20 & 20 & $137.71 \pm 1.62$ & $25.99 \pm 0.52$ & $19.55 \pm 1.23$ & $0.58 \pm 0.51$ & $46.13 \pm 2.06$ & $3.08 \pm 0.27$ & $4.67 \pm 0.16$ & $45.54 \pm 1.75$ & $2.37 \pm 0.24$ \\
\hline 2 & 40 & 20 & $190.16 \pm 3.09$ & $26.04 \pm 0.79$ & $13.73 \pm 0.79$ & $0.61 \pm 0.02$ & $52.82 \pm 0.37$ & $2.85 \pm 0.16$ & $3.95 \pm 0.27$ & $39.77 \pm 0.24$ & $3.86 \pm 0.25$ \\
\hline
\end{tabular}

${ }^{\mathrm{a}}$ Of total products $(\mathrm{mol} / 100 \mathrm{~mol})$.

${ }^{\mathrm{b}}$ Molar percentage of ethanol (Eth) and acetate (AA) over total products.

${ }^{\mathrm{c}}$ Molar ratio of butyrate (BA) to acetate (AA).

${ }^{\mathrm{d}}$ Mean value \pm standard deviation, $n=3-6$.

${ }^{\mathrm{e}}$ Undetectable. 
accounting for molar percentages of 31.0-58.8\%, 13.7-50.3\%, and $11.5-26.0 \%$ of the total soluble metabolic products identified, respectively. Notably, propionate proportion was very low, and even undetectable in some runs. This is probably owing to the washout of propionate producers as a result of the hydrodynamic selection on the mixed populations during the period of cultivation as noted in a previous study [4]. The amount of overall metabolites increased significantly with the HRT and influent glucose concentration for a given OLR. At an OLR of $5 \mathrm{~g}$-glucose $/ \mathrm{Lh}$, for example, total metabolites reached $73.0 \mathrm{mM}$ at an HRT of $2 \mathrm{~h}$ and an influent glucose concentration of $10 \mathrm{~g} / \mathrm{L}$. These decreased to $18.0 \mathrm{mM}$ as the HRT and influent glucose concentration reduced to $0.5 \mathrm{~h}$ and $2.5 \mathrm{~g} / \mathrm{L}$, respectively. Butyrate was predominated over acetate and ethanol, with an average proportion of $50.8 \pm 5.6 \%$ in a range of $37.0-53.7 \%$ at the OLRs larger than $2.5 \mathrm{~g}$-glucose $/ \mathrm{Lh}$, while acetate became more predominant $(38.5-50.3 \%)$, followed by butyrate $(31.0-37.7 \%)$ and ethanol $(11.5-18.7 \%)$ at an OLR of $2.5 \mathrm{~g}$-glucose $/ \mathrm{L} \mathrm{h}$. These results implied that a shift of metabolic pathways might occur with the reduction of OLR to a certain extend (2.5 g-glucose/g-glucose/L $\mathrm{h}$ in the present study). It was interesting to note that the sum of acetate and ethanol was relatively consistent, with an average of $38.0 \%$ of the total metabolites as the OLR fell in the range of 5-20 g-glucose $/ \mathrm{L} \mathrm{h}$. Also the ethanol proportion increased, corresponding to a decrease in acetate with increasing influent glucose concentration. This tendency was especially obvious as the influent glucose concentration was larger than $10 \mathrm{~g} / \mathrm{L}$.

High proportion of butyrate revealed that the microbial reaction continued after butyrate fermentation over the OLR range of 5-20 g-glucose/L h. Clostridium species are, therefore, considered to be predominant in the reactor cultures because these micro-organisms are responsible for the production of butyrate [26]. The ratio of butyrate/acetate is considered a predictor of microbial yield of hydrogen. In the present study, butyrate/acetate ratio was in the range of 2.1-3.9 at OLRs larger than $2.5 \mathrm{~g}$-glucose/Lh (Table 2), which was generally in agreement with values (2.1-5.9) reported in other studies [4,28-30]; the corresponding hydrogen yields $(0.8-1.8 \mathrm{~mol}-$ $\mathrm{H}_{2}$ /mol-glucose) obtained in the present study were also in line with those reported between 0.7 and $1.9 \mathrm{~mol}-\mathrm{H}_{2} / \mathrm{mol}$-glucose. Reducing OLR to a level of $2.5 \mathrm{~g}$-glucose $/ \mathrm{Lh}$ resulted in a significant increase in acetate proportion, indicating that a metabolic shift might occur. As a result, an enhanced hydrogen yield would have been expected because hydrogen production from glucose would increase by one-fold when acetate, instead of butyrate is produced. However, the hydrogen yields were found otherwise. The underlying causes for the inferior yields will be discussed subsequently.

\subsection{Carbon balance}

A mass balance of carbon was analyzed for 13 runs as tabulated in Table 3. In a strict anaerobic hydrogen fermenter, there was no additional carbon source other than that derived from the substrate. The carbons from the nutrients and dissolved $\mathrm{CO}_{2}$ in the effluent were ignored and thus they were not included in the analysis. The composition of biomass was assumed to be $\mathrm{C}_{5} \mathrm{H}_{7} \mathrm{O}_{2} \mathrm{~N}[10,15]$. The influent carbon was assumed to be converted into biomass, biogas $\left(\mathrm{CO}_{2}\right)$ and effluent TOC in terms of residual glucose, VFAs, ethanol, and soluble microbial products (SMPs). In the present study, SMPs were not monitored separately. The soluble effluent carbon was quantified on the basis of either the overall TOC or its specific effluent components as residual glucose, VFAs and ethanol. This results in two different stoichiometric equations as shown in Eqs. (1) and (2).

Recovery 1

$$
\begin{aligned}
= & {\left[(\text { effluent TOC }) /(\mathrm{HRT})+\left(\mathrm{CO}_{2} \text { production rate }\right)\right.} \\
& \cdot(\text { carbon molecular weight }) /(24.45 \mathrm{~L} / \mathrm{mol}) \\
& +(\text { Effluent VSS }) \cdot(\text { carbon molar ratio }) / 1000] \\
& /(\text { OLR })
\end{aligned}
$$

\section{Recovery 2}

$$
\begin{aligned}
= & {[(\text { residual glucose }) /(\mathrm{HRT})+(\mathrm{VFA}+\text { ethanol }) /(\mathrm{HRT})} \\
& +\left(\mathrm{CO}_{2} \text { production rate }\right) \cdot(\text { carbon molecular } \\
& \text { weight }) /(24.45) \\
& +(\text { Effluent } \mathrm{VSS}) \cdot(5 \cdot \text { carbon molecular weight }) \\
& /(\text { carbon molar ratio }) / 1000] /(\mathrm{OLR}) .
\end{aligned}
$$

As shown in Table 3, the recoveries of the carbon mass were relatively high according to Eq. (1) (Recovery 1) for the OLRs over $2.5 \mathrm{~g}$-glucose $/ \mathrm{L} \mathrm{h}$, ranging from $91.1 \%$ to $107.9 \%$, while satisfactory recoveries $(89.2-107.0 \%)$ were only found for OLR in a range of 5-20 g-C/L h based on Eq. (2) (Recovery 2). It was noted that the recoveries at some runs were larger than $100 \%$, probably due to the deviation from the assumed culture formula. Recoveries of glucose carbon in a range of $41.4-47.7 \%$ obtained at the OLR of $2.5 \mathrm{~g}$-glucose $/ \mathrm{L} \mathrm{h}$ indicated that unidentified products accounted for more than half of the total carbon flow. These unidentified products were probably contributed by the SMPs and other end products which were difficult to be detected by the present analytical methods [31].

Obviously, the carbon fate was dependent on the OLR. About 26-29\% of the influent carbon was converted into fermentation products at the lowest OLR of $2.5 \mathrm{~g}$-glucose $/ \mathrm{L} \mathrm{h}$, while it increased to $65-79 \%$ and $47-66 \%$ at the OLRs of 5-10 and $20 \mathrm{~g}$-glucose $/ \mathrm{Lh}$, respectively. In addition, approximately $4-14 \%$ influent carbon was found in the form of biomass.

The effect of OLR on hydrogen yield had been investigated, and the OLR was correlated with hydrogen yield $[7,18]$. However, since hydrogen yield essentially represents the microbial conversion capability of hydrogen from organic materials, it is likely that biomass concentration affects the hydrogen yield. Sludge loading rate (SLR, g-glucose/g-VSS h) or the food to microorganism (F/M) ratio, defined as the amount of substrate applied to per unit mass of VSS per hour, is expressed as

$\operatorname{SLR}=\frac{Q S_{0}}{M_{\mathrm{VSS}}}=\frac{Q S_{0}}{V X}=\operatorname{OLR} \frac{1}{X}$,

where $Q$ is flow rate $(\mathrm{L} / \mathrm{h}), S_{0}$, glucose concentration $(\mathrm{g} / \mathrm{L})$; $M_{\mathrm{VSS}}$, the amount of VSS (g), $V$, reactor volume (L); OLR, organic loading rate (g-glucose/Lh); and $X$, biomass 
Table 3

Carbon balance for hydrogen fermentation using granular sludge

\begin{tabular}{|c|c|c|c|c|c|c|c|c|c|}
\hline HRT (h) & $\begin{array}{l}\text { Influent glucose } \\
(\mathrm{g}-\mathrm{C} / \mathrm{L})\end{array}$ & $\begin{array}{l}\text { OLR } \\
(\mathrm{g}-\mathrm{C} / \mathrm{Lh})\end{array}$ & $\begin{array}{l}\text { Effluent TOC } \\
(\mathrm{g} / \mathrm{L})\end{array}$ & $\begin{array}{l}\mathrm{CO}_{2} \text { production rate } \\
(\mathrm{L} / \mathrm{L} h)\end{array}$ & $\begin{array}{l}\text { Effluent VSS } \\
(\mathrm{mg} / \mathrm{L})\end{array}$ & $\begin{array}{l}\text { Residual glucose } \\
\text { (g-C/L) }\end{array}$ & $\begin{array}{l}\text { VFAs } \pm \text { ethanol } \\
(\mathrm{g}-\mathrm{C} / \mathrm{L})\end{array}$ & $\begin{array}{l}\text { Recovery } \\
1(\%)\end{array}$ & $\begin{array}{l}\text { Recovery } \\
2(\%)\end{array}$ \\
\hline 1 & 1 & 1 & $\begin{array}{c}0.76 \\
(76.1 \%)^{b}\end{array}$ & $\begin{array}{c}0.09 \\
(4.6 \%)\end{array}$ & $\begin{array}{l}196.67 \\
(10.4 \%)\end{array}$ & $\begin{array}{c}0.00 \\
(0.4 \%)\end{array}$ & $\begin{array}{c}0.26 \\
(26.0 \%)\end{array}$ & 91.09 & 41.43 \\
\hline 2 & 2 & 1 & $\begin{array}{c}1.58 \\
(79.1 \%)\end{array}$ & $\begin{array}{c}0.16 \\
(7.8 \%)\end{array}$ & $\begin{array}{l}357.78 \\
\quad(9.5 \%)\end{array}$ & $\begin{array}{c}0.02 \\
(0.9 \%)\end{array}$ & $\begin{array}{c}0.59 \\
(29.6 \%)\end{array}$ & 96.39 & 47.73 \\
\hline 0.5 & 1 & 2 & $\begin{array}{c}0.74 \\
(74.2 \%)\end{array}$ & $\begin{array}{c}0.49 \\
(11.9 \%)\end{array}$ & $\begin{array}{l}265.56 \\
(14.1 \%)\end{array}$ & $\begin{array}{c}0.00 \\
(0.5 \%)\end{array}$ & $\begin{array}{c}0.73 \\
(73.2 \%)\end{array}$ & 100.21 & 99.66 \\
\hline 1 & 2 & 2 & $\begin{array}{c}1.39 \\
(69.3 \%)\end{array}$ & $\begin{array}{c}0.70 \\
(17.1 \%)\end{array}$ & $\begin{array}{l}472.22 \\
(12.5 \%)\end{array}$ & $\begin{array}{c}0.06 \\
(3.0 \%)\end{array}$ & $\begin{array}{c}1.30 \\
(64.8 \%)\end{array}$ & 98.91 & 97.41 \\
\hline 2 & 4 & 2 & $\begin{array}{c}3.00 \\
(75.0 \%)\end{array}$ & $\begin{array}{c}0.83 \\
(20.4 \%)\end{array}$ & $\begin{array}{l}261.83 \\
(3.5 \%)\end{array}$ & $\begin{array}{c}0.03 \\
(0.6 \%)\end{array}$ & $\begin{array}{c}2.94 \\
(73.5 \%)\end{array}$ & 98.82 & 98.01 \\
\hline 0.25 & 1 & 4 & $\begin{array}{c}0.79 \\
(78.5 \%)\end{array}$ & $\begin{array}{c}1.16 \\
(14.2 \%)\end{array}$ & $\begin{array}{c}0.18 \\
(9.5 \%)\end{array}$ & $\begin{array}{c}0.02 \\
(2.0 \%)\end{array}$ & $\begin{array}{c}0.77 \\
(77.2 \%)\end{array}$ & 102.23 & 102.91 \\
\hline 0.5 & 2 & 4 & $\begin{array}{c}1.43 \\
(71.3 \%)\end{array}$ & $\begin{array}{c}1.26 \\
(15.4 \%)\end{array}$ & $\begin{array}{l}348.15 \\
\quad(9.2 \%)\end{array}$ & $\begin{array}{c}0.03 \\
(1.4 \%)\end{array}$ & $\begin{array}{c}1.36 \\
(68.0 \%)\end{array}$ & 95.99 & 94.02 \\
\hline 1 & 4 & 4 & $\begin{array}{c}3.12 \\
(78.1 \%)\end{array}$ & $\begin{array}{c}1.36 \\
(16.7 \%)\end{array}$ & $\begin{array}{r}562.73 \\
(7.5 \%)\end{array}$ & $\begin{array}{c}0.39 \\
(9.7 \%)\end{array}$ & $\begin{array}{c}2.75 \\
(68.8 \%)\end{array}$ & 102.28 & 102.65 \\
\hline 2 & 8 & 4 & $\begin{array}{c}6.46 \\
(80.7 \%)\end{array}$ & $\begin{array}{c}1.71 \\
(21.0 \%)\end{array}$ & $\begin{array}{l}933.33 \\
(6.2 \%)\end{array}$ & $\begin{array}{c}0.08 \\
(1.0 \%)\end{array}$ & $\begin{array}{c}6.30 \\
(78.9 \%)\end{array}$ & 107.89 & 106.99 \\
\hline 0.25 & 2 & 8 & $\begin{array}{c}1.40 \\
(70.0 \%)\end{array}$ & $\begin{array}{c}1.52 \\
(9.3 \%)\end{array}$ & $\begin{array}{l}502.23 \\
(13.3 \%)\end{array}$ & $\begin{array}{c}0.57 \\
(28.4 \%)\end{array}$ & $\begin{array}{c}0.95 \\
(47.7 \%)\end{array}$ & 92.72 & 98.69 \\
\hline 0.5 & 4 & 8 & $\begin{array}{c}3.21 \\
(80.2 \%)\end{array}$ & $\begin{array}{c}1.85 \\
(11.3 \%)\end{array}$ & $\begin{array}{l}615.63 \\
(8.2 \%)\end{array}$ & $\begin{array}{c}1.40 \\
(35.0 \%)\end{array}$ & $\begin{array}{c}2.08 \\
(52.1 \%)\end{array}$ & 99.68 & 106.59 \\
\hline 1 & 8 & 8 & $\begin{array}{c}6.96 \\
(87.1 \%)\end{array}$ & $\begin{array}{c}2.22 \\
(13.6 \%)\end{array}$ & $\begin{array}{r}700.95 \\
(4.7 \%)\end{array}$ & $\begin{array}{c}1.86 \\
(23.3 \%)\end{array}$ & $\begin{array}{c}5.30 \\
(66.3 \%)\end{array}$ & 105.31 & 107.81 \\
\hline 2 & 16 & 8 & $\begin{array}{c}13.87 \\
(86.7 \%)\end{array}$ & $\begin{array}{c}1.39 \\
(8.5 \%)\end{array}$ & $\begin{array}{r}1055.40 \\
(3.5 \%)\end{array}$ & $\begin{array}{c}4.80 \\
(30.0 \%)\end{array}$ & $\begin{array}{c}7.54 \\
(47.2 \%)\end{array}$ & 98.70 & 89.16 \\
\hline
\end{tabular}

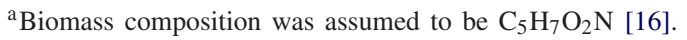

${ }^{\mathrm{b}}$ Carbon distribution of effluent products over the influent carbon.

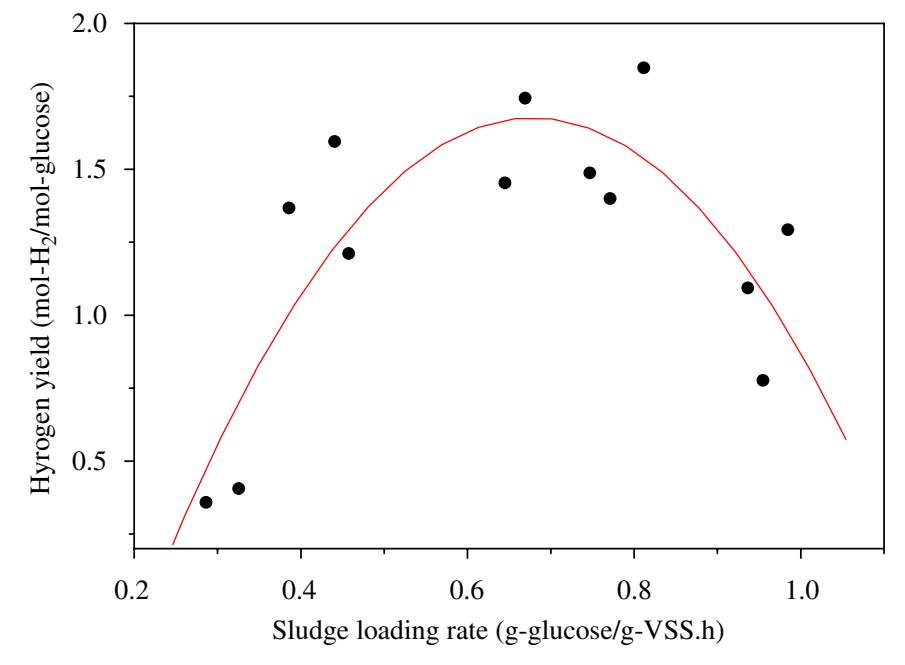

Fig. 8. Hydrogen yield as a function of sludge loading rate $(p=0.003)$.

concentration ( $\mathrm{g}-\mathrm{VSS} / \mathrm{L})$. Obviously, SLR is a function of OLR and biomass concentration. This understanding may help to regulate hydrogen fermentation. Fig. 8 illustrates that hydrogen yield was a function of SLR. In the present study, the optimum SLR for hydrogen yield was found in a range of $0.6-0.8 \mathrm{~g}$-glucose/g-VSSh. This is in agreement with the reported maximum hydrogen yield at SLR ranging from 0.8 to $1.2 \mathrm{~g}$-glucose/g-VSS h $[2,4,23]$. There is a lack of agreement, however, with the work conducted by Van Ginkel and Logan [7], in which maximum hydrogen yield was achieved at an SLR of about $0.1 \mathrm{~g}$-glucose $/ \mathrm{g}$-VSS $\mathrm{h}$. The inconsistency indicates that the hydrogen yield might be influenced by culture conditions and other environmental factors.

Reducing OLR at a given amount of biomass, i.e. reducing SLR might result in the culture underfed and hence metabolic shift. It is well noted that influent substrate tends to be converted to energy for microbial maintenance, rather than to end products as the culture remains starved [32]. In fact, it was found that half of the glucose carbon, based on carbon balance analysis of individual products as discussed earlier, shift towards the formation of unidentified products which were unable to be detected by the current analytical methods. These unidentified products, which could be fermentation byproducts, such as ketones and aldehydes, or compounds produced, secreted and released by micro-organisms, were unfavorable or less favorable for hydrogen production [31]. From these experimental results, it was deduced that relatively low hydrogen yield obtained at an OLR of $2.5 \mathrm{~g}$-glucose/ $\mathrm{L} \mathrm{h}$ was possibly attributed to the metabolic shift induced by the reduced SLR. 


\section{Conclusions}

From the results obtained in the present study the following conclusions can be made.

Peak hydrogen yield and hydrogen production rate at a given OLR over a range of 2.5-20 g-glucose/L h corresponded to an increase of OLR. The optimum operating conditions were suggested at an OLR of $20 \mathrm{~g}$-glucose/L h, corresponding to an HRT of $0.5 \mathrm{~h}$ and an ISC of $10 \mathrm{~g}$-glucose $/ \mathrm{L}$, where both hydrogen yield and hydrogen production rate reached the maximum values of $1.84 \mathrm{~mol}-\mathrm{H}_{2} / \mathrm{mol}$-glucose and $3.26 \mathrm{~L} / \mathrm{Lh}$, respectively. In addition to OLR, hydrogen production is also influenced by HRT and ISC which were interrelated and had a combined influence on hydrogen yield. An appropriate control of HRT, substrate concentration and the associated OLR is crucial. Ignoring any of these parameters might result in an inferior performance of the biosystems. A substantial decrease in hydrogen production was noted as the reactor was operated at an HRT of $0.25 \mathrm{~h}$ at any other substrate concentration, or at an HRT of $1 \mathrm{~h}$ at $20 \mathrm{~g}$-glucose/L, or at an HRT of $2 \mathrm{~h}$ at $40 \mathrm{~g}$-glucose/L.

Butyrate, acetate and ethanol were the major soluble metabolite products. Butyrate was the predominant product over acetate and ethanol, with an average molar proportion of $50.8 \%$ of the total volatile fatty acids and ethanol at the OLRs larger than $2.5 \mathrm{~g}$-glucose/L h, while acetate became predominant $(38.5-50.3 \%)$ at an OLR of $2.5 \mathrm{~g}$-glucose/L h. Carbon balance analysis showed that more than half of the glucose carbon was converted into unknown soluble products at an OLR of $2.5 \mathrm{~g}$-glucose/Lh. Metabolic shift of microbial reactions for hydrogen fermentation was likely to occur with the reduction of OLR to $2.5 \mathrm{~g}$-glucose/Lh. It was found that high yield of hydrogen coincided with a sludge loading rate of 0.6-0.8 g-glucose/g-VSSh, and substantial decrease in hydrogen yield occurred as the sludge loading rate fell beyond the range. It is deduced that decreasing the sludge loading rate induced the metabolic shift of microbial reactions at an OLR of $2.5 \mathrm{~g}$-glucose/L h, which resulted in a substantial reduction in hydrogen yield to $0.36-0.41 \mathrm{~mol}_{-} \mathrm{H}_{2} / \mathrm{mol}$-glucose.

Formation of granular sludge significantly increased the overall reactor biomass concentration to as much as $16.0 \mathrm{~g}-\mathrm{VSS} / \mathrm{L}$, which enabled the CSTR to operate at an OLR of up to $20 \mathrm{~g}$-glucose/ $\mathrm{Lh}$ and hence enhanced the performance in hydrogen production. The granule-based CSTR in the present study was demonstrated to be a promising biosystem for hydrogen production.

\section{References}

[1] Das D, Veziroglu TN. Hydrogen production by biological processes: a survey of literature. Int J Hydrogen Energy 2001;26(1):13-28.

[2] Lin C-Y, Chang R-C. Fermentative hydrogen production at ambient temperature. Int J Hydrogen Energy 2004;29(7):715-20.

[3] Khanal SK, Chen WH, Li L, Sung SW. Biological hydrogen production: effects of $\mathrm{pH}$ and intermediate products. Int $\mathrm{J}$ Hydrogen Energy 2004;29(11):1123-31.

[4] Zhang ZP, Show KY, Tay JH, Liang DT, Lee DJ, Jiang WJ. Effect of hydraulic retention time on biohydrogen production and anaerobic microbial community. Process Biochem 2006;41(10):2118-23.
[5] Levin DB, Pitt L, Love M. Biohydrogen production: prospects and limitations to practical application. Int $\mathbf{J}$ Hydrogen Energy 2004;29(2):173-85.

[6] Kim SH, Han SK, Shin HS. Effect of substrate concentration on hydrogen production and 16S rDNA-based analysis of the microbial community in a continuous fermenter. Process Biochem 2006;41(1):199-207.

[7] Van Ginkel SW, Logan B. Increased biological hydrogen production with reduced organic loading. Water Res 2005;39(16):3819-26.

[8] Yu H, Zhu Z, Hu W, Zhang H. Hydrogen production from rice winery wastewater in an upflow anaerobic reactor by using mixed anaerobic cultures. Int J Hydrogen Energy 2002;27(11-12):1359-65.

[9] Fan KS, Kan NR, Lay JJ. Effect of hydraulic retention time on anaerobic hydrogenesis in CSTR. Bioresoure Technol 2006;97(1):84-9.

[10] Oh YK, Kim SH, Kim MS, Park S. Thermophilic biohydrogen production from glucose with trickling biofilter. Biotechnol Bioeng 2004;88(6): $690-8$.

[11] Chang JS, Lee KS, Lin PJ. Biohydrogen production with fixed-bed bioreactors. Int J Hydrogen Energy 2002;27(11-12):1167-74.

[12] Wu SY, Lin CN, Chang JS. Hydrogen production with immobilized sewage sludge in three-phase fluidized-bed bioreactors. Biotechnol Prog 2003;19(3):828-32.

[13] Yu HQ, Mu Y. Biological hydrogen production in a UASB reactor with granules. II: reactor performance in 3-year operation. Biotechnol Bioeng 2006;94(5):988-95.

[14] Fang HHP, Liu H, Zhang T. Characterization of a hydrogen-producing granular sludge. Biotechnol Bioeng 2002;78(1):44-52.

[15] Liu H, Fang HHP. Hydrogen production from wastewater by acidogenic granular sludge. Wat Sci Technol 2003;47(1):153-8.

[16] Fang HHP, Liu H. Effect of $\mathrm{pH}$ on hydrogen production from glucose by a mixed culture. Bioresource Technol 2002;82(1):87-93.

[17] Lee KS, Wu JF, Lo YS, Lo YC, Lin PJ, Chang JS. Anaerobic hydrogen production with an efficient carrier-induced granular sludge bed bioreactor. Biotechnol Bioeng 2004;87(5):648-57.

[18] Zhang ZP, Tay JH, Show KY, Yan R, Liang DT, Lee DJ. et al. Biohydrogen production in a granular activated carbon anaerobic fluidized bed reactor. Int J Hydrogen Energy 2007;32(2):185-91.

[19] Zhang ZP, Show KY, Tay JH, Liang DT, Lee DJ, Jiang WJ. Rapid formation of hydrogen-producing granules in an anaerobic continuous stirred tank reactor induced by acid incubation. Biotechnol Bioeng 2007;96(6):1040-50.

[20] Dubois M, Gilles KA, Hamilton JK, Rebers PA, Smith F. Colorimetric method for determination of sugars and related substrates. Anal Chem 1956;28(3):350-6.

[21] APHA. Standard methods for the examination of water and wastewater, 20th ed. Washington DC, USA: American Public Health Association; 1998.

[22] Kumar N, Das D. Continuous hydrogen production by immobilized Enterobacter cloacae IIT-BT 08 using lignocellulosic materials as solid matrices. Enzyme Microb Tech 2001;29(4-5):280-7.

[23] Lin CY, Chang RC. Hydrogen production during the anaerobic acidogenic conversion of glucose. J Chem Technol Biotechnol 1999; 74(6):498-500.

[24] Van Den Heuve JC, Beeftink HH. Kinetic effects of simultaneous inhibition by substrate and product. Biotechnol Bioeng 1988;31(7): 718-24.

[25] Rachman MA, Nakashimada Y, Kakizono T, Nishio N. Hydrogen production with high yield and high evolution rate by self-flocculated cells of Enterobacter aerogenes in a packed-bed reactor. Appl Microbiol Biot 1998;49(4):450-4.

[26] Chang FY, Lin CY. Biohydrogen production using an up-flow anaerobic sludge blanket reactor. Int J Hydrogen Energy 2004;29(1):33-9.

[27] Wu SY, Hung CH, Lin CN, Chen HW, Lee AS, Chang JS. Fermentative hydrogen production and bacterial community structure in highrate anaerobic bioreactors containing silicone-immobilized and selfflocculated sludge. Biotechnol Bioeng 2006;93(5):934-46.

[28] Chen CC, Lin CY, Chang JS. Kinetics of hydrogen production with continuous anaerobic cultures utilizing sucrose as the limiting substrate. Appl Microbiol Biot 2001;57(1-2):56-64. 
[29] Kim IS, Hwang MH, Jang NJ, Hyun SH, Lee ST. Effect of low pH on the activity of hydrogen utilizing methanogen in bio-hydrogen process. Int J Hydrogen Energy 2004;29(11):1133-40.

[30] $\mathrm{Mu} \mathrm{Y,} \mathrm{Yu} \mathrm{HQ,} \mathrm{Wang} \mathrm{Y.} \mathrm{The} \mathrm{role} \mathrm{of} \mathrm{pH}$ in the fermentative $\mathrm{H}_{2}$ production from an acidogenic granule-based reactor. Chemosphere 2006;64(3): 350-8.
[31] Fang HHP, Yu HQ. Effect of HRT on mesophilic acidogenesis of dairy wastewater. J Environ Eng-ASCE 2000;126(12):1145-8.

[32] Rittmann BE, McCarty PL. Environmental biotechnology: principles and applications. Boston: McGraw-Hill Inc.; 2001. 